\title{
CONCEPTOS HISTÓRICO-CRÍTICOS PRELIMINARES A LA PROPUESTA DE REFORMA DEL MELODRAMA DE ESTEBAN DE ARTEAGA
}

\author{
Fernando Molina Castillo
}

Este artículo condensa los presupuestos esenciales para afrontar la lectura y el análisis crítico de una de las aportaciones más valiosas en el campo de la crítica del melodrama en Italia en el siglo XVIII. Nos referimos a Le Rivoluzioni del teatro musicale italiano, obra en tres volúmenes del español Esteban de Arteaga ${ }^{1}$, publicada en Bolonia en los años 1783, 1785 y 1788, respectivamente, y reeditada en Venecia entre los años 1785 y 1787. La gran extensión de la obra, así como su complejidad conceptual, al aglutinar contenidos de índole filosófico-estética, histórica y crítica, en una época de particular agitación de ideas por toda Europa, aconseja dotarse previamente de un conocimiento sucinto del estado de la cuestión anterior a la publicación de la obra. Ello permitirá, además, conocer el grado efectivo de originalidad de las ideas allí expuestas, así como su difusión y repercusión. De este empeño surge este trabajo, como primer paso dentro de un más amplio proyecto de análisis de la obra italiana de Arteaga.

\footnotetext{
${ }^{1}$ Esteban de Arteaga (Segovia, 1747 - París, 1798) fue uno de los tantos intelectuales españoles que, por su condición de jesuitas, se vieron obligados a abandonar España en virtud de la orden real de Carlos III de 1767 que así lo decretaba. Fue a establecerse en Italia, siguiendo a la mayoría de aquel numeroso grupo (acerca de la historia y el valor intelectual de esta diáspora existe un gran estudio de M. Batllori, La cultura hispano-italiana de los jesuitas expulsos, Madrid, Gredos, 1966) y pronto se introdujo en los ambientes intelectuales y literarios de aquel país. De carácter fogoso y proclive a la polémica, sus escritos bien pronto le granjearon popularidad en dichos ambientes, unas veces en sentido favorable y otras en sentido adverso, y este motivo, unido a otras circustancias personales, le obligó a cambiar de residencia en dos ocasiones: de Bolonia a Venecia, y posteriormente a Roma. Mantuvo interesantes carteos con intelectuales de la época, tanto italianos como del resto de Europa. Fruto de su interés por el melodrama, que le surgió a raíz de su amistad con el padre Martini, en la universidad de Bolonia, es su más importante obra, la ya citada Le Rivoluzioni del teatro musicale italiano, que actualmente cuenta con una edición facsímil (Bolonia, Forni Editore, 1969) que reproduce la edición boloñesa y un apéndice que incluye las adiciones, correcciones y variaciones de la edición veneciana. Otras obras fundamentales de Arteaga son: las Investigaciones filosóficas sobre la Belleza Ideal, considerada como objeto de todas las artes de imitación, escrita en Roma y publicada en Madrid en castellano en 1789. Modernamente está editada a cargo del citado M. Batllori (Madrid, Espasa-Calpe, 1972), en cuyo prólogo se dan más detalles sobre la vida y la obra de Arteaga; las Lettere musico-filologiche y las disertaciones Del ritmo sonoro e del ritmo muto nella musica degli antichi, ambas redactadas en los últimos años de su vida e incompletas. La primera edición de estas obras también ha corrido a cargo de M. Batllori, en Madrid, CSIC, 1944.
} 


\section{Génesis del melodrama: entre humanismo y racionalismo.}

Aquel viejo ideal del humanismo de recuperar la gramática de las lenguas clásicas como primer paso para rescatar y revivir en Europa el esplendor de la civilización grecorromana, constituía un anhelo consciente y programado que supondría cerrar un paréntesis medio entre dos épocas doradas, una que ya había pasado y otra que estaba por venir, un paréntesis que se asociaba sin más a la escolástica, la barbarie, los galos, que irremediablemente, profetizaba Petrarca, habían de ser derrotados de nuevo por los italianos ${ }^{2}$. Por entonces se había hecho evidente que el latín mantenido durante toda la Edad Media había sido adulterado inconscientemente y estaba bien lejos del verdadero latín, el clásico, y tal convencimiento llevó a la necesidad urgente de depurar aquel latín, por medio de una ciencia de los textos o filología. En sucesivos pasos, el programa humanista, con la llave del latín, se encargaría de ir restaurando, como si se tratara de un cuadro cuyos colores y dibujo se han borrado con los años, todas las demás disciplinas del hombre, entre las cuales estaban las artes.

Es en esta clave como debemos entender la restauración de lo clásico en el ámbito de la estética musical moderna, en gran parte fruto del pensamiento racionalista y la obra del humanista veneciano G. Zarlino (1517-1590) ${ }^{3}$, quien partió del convencimiento de que la evolución de la teoría musical griega a lo largo de la Edad Media había desembocado en un oscurecimiento de la misma y en una supresión intencionada de su finalidad práctica, quedando reducida a un laberinto de reflexiones metafísicas consideradas en sí mismas el verdadero arte musical, mientras que la práctica musical no era más que un oficio artesano de baja condición ${ }^{4}$. Este redescubrimiento de la armonía como ciencia musical con fines prácticos fue la primera piedra en la construcción de una estética musical clasicista, construcción que resultó más ardua que en las demás artes, ya que mientras en éstas se conservaban los modelos, en la música tan sólo se disponía de vagas y no siempre rigurosas noticias. A finales del siglo XVI, los miembros de la Camerata de los Bardi, sintiéndose

2 "En vano se buscará en las Galias quien sepa nada de nada. Pues, ¿qué hay en las artes liberales, en las ciencias de la naturaleza, en la historia, en la elocuencia, en la moral, que no se deba a los italianos? [...] ¿Quiénes sino los italianos han creado los dos derechos? ¿Dónde han nacido o vivido los doctores de la Iglesia? ¿A qué oradores y poetas se encontrará fuera de Italia? Tenía que ser así, porque solo en el latín, en las "latine litere", está la raíz de todas las artes y el fundamento de todas las ciencias, [...]. A tanta riqueza nada puede oponer la Galia, salvo las voces chillonas de la rue de Fouarre" (Paráfrasis de un fragmento de la carta de Petrarca a Urbano V, en 1368, en F. Rico, El sueño del humanismo, Madrid, Alianza, 1993, p. 21).

3 Institutioni armoniche (1558), Dimostrationi harmoniche (1571) y Sopplimenti musicali (1588). Todas estas obras fueron publicadas en Venecia.

4 Vincenzo Galilei, padre de Galileo, el más importante teórico del grupo de humanistas reunidos en torno al conde Giovanni Bardi (la "Camerata de Bardi", inventores del melodrama, en la que estaban también Jacopo Peri, Ottavio Rinuccini, Giulio Caccini, Claudio Monteverdi), nos ofrece esta interpretación negligente de la Edad Media de forma explícita: "Habiendo padecido Italia grandes invasiones de los bárbaros por largo espacio de tiempo, llegó a consumirse cualquier vestigio de ciencia y, como si hubieran sido sorprendidos de pronto por un grave letargo de ignorancia, los hombres vivieron sin ningun deseo de saber; de la música se tenían las mismas noticias que de las Indias Occidentales, y en tal ceguera perseveraron hasta que, primeramente Gaffurio, después Glaureano y por último Zarlino, comenzaron a investigar sobre lo que la música fuera y a procurar sacarla de las tinieblas en las que se hallaba sepultada" (Dialogo della musica antica e della moderna, Venecia, 1581. Cito por E. Fubini, La estética musical desde la Antigüedad hasta el siglo XX, Madrid, Alianza, 1991, $3^{\text {a }}$ ed., p. 142). 
parcialmente herederos de las ideas de Zarlino, dan vida al proyecto del retorno a lo clásico en la música, con la invención del melodrama, un género teatral con acompañamiento musical ${ }^{5}$. Para que el melodrama brotara había sido necesaria la confluencia de varias condiciones que el humanismo había sido capaz de reunir. En primer lugar, el descrédito de la polifonía medieval, en cuanto portadora de la tendencia de la música a su autonomía respecto de la poesía. Ciertamente, en la polifonía y el contrapunto medievales el efecto producido en el oyente era de confusión, una maraña de voces y tonos contradictorios que no contribuían en nada a comunicar algo; constituían, por consiguiente, algo irracional y condenable, tanto desde el punto de vista ético-religioso ${ }^{6}$, como desde el punto de vista filosófico-literario ${ }^{7}$. En segundo lugar, el componente aristotélico de los humanistas indujo a éstos a recuperar la concepción laica y hedonista de la música, la exigencia de que el arte musical debe deleitar al oyente, para lo cual era necesario que el compositor dispusiera de un sistema racional, la armonía, que le permitiera crear una música que, sin ninguna $d u d a$, produciría en el oyente el efecto deseado ${ }^{8}$. Con esta inquietud se legitimaba la importancia del público, una - posiblemente la más importante - de las claves del éxito del melodrama. Pero ambos puntos de vista, unidos en un primer momento a favor de una misma causa, es decir, la de retornar a la claridad de la teoría musical clásica, perdida en el Medievo, no

${ }^{5}$ El primer melodrama de la historia fue Dafne, obra del poeta Ottavio Rinuccini y musicada por Jacopo Peri. Se representó en privado en 1595 y en público tres años después. Sobre los detalles acerca de este acontecimiento, vid. R. Tedeschi, "L'Opera italiana", en Storia d'Italia. I documenti, vol. 5, tomo II, Torino, Einaudi, 1973, p. 1145 y ss.

${ }^{6}$ El espíritu de la Contrarreforma participaba de la idea platónico-racionalista de la música como potencial fuente de placer y, por consiguiente, afirmaba que era necesario encauzarla y controlarla para evitar que se desligara del lenguaje. Por el contrario, Lutero se mostró mucho más moderno al considerar, de una forma semejante a la que adoptarían los románticos, que "gracias a la música, se olvidan la cólera y los demás vicios, motivo por el que digo plenamente convencido, sin temor alguno, que, desde el punto de vista teológico, ningún arte puede alcanzar el nivel de la música" (Carta a Senfl, 1530. Cito por E. Fubini, op. cit., p. 154. El subrayado es nuestro). Esta es, en buena parte, la clave del origen del desarrollo de la música sinfónica, ya desde el siglo XVII, en los países protestantes, y su retraso en los países católicos.

7 "En el Diálogo della musica antica e della moderna (1581) V. Galilei afirmaba que los sonidos instrumentales producidos por simples piezas 'de madera hueca sobre la que se tensan cuatro, seis, o más cuerdas hechas con las tripas de una bestia muda' no pueden convenir a la dignidad de la voz. Además, los ritmos, las melodías y tempos desiguales, y la confusión de voces de la polifonía impiden la comunicación. El canto polifónico moderno es 'absurdo' y ofrece un placer vacuo. El contrapunto permite que 'los sentidos dominen a la razón, la materia a la forma y lo falso a lo verdadero'. Las reglas de la armonía sirven para deleitar y 'cosquillear' al oído, 'pero para la expresión de conceptos no son más que pestilencias', porque la mente, 'atrapada en los cepos del placer, no tiene tiempo de entender ni considerar las palabras mal pronunciadas. La composición polifónica debe ceder su puesto a un estilo monódico, porque 'la verdad es una unidad' y sólo una voz que no esté envuelta en una maraña de sonidos puede comunicarse con claridad" (J. Neibauer, La emancipación de la música. El alejamiento de la mímesis en la estética del siglo XVIII, Madrid, Visor, 1992, pp. 49-50. Vid. también J. Zamacois, Temas de estética y de historia de la música, Barcelona, Labor, 1990, 4ª ed., pp. 40-1).

8 "Así como al Poeta lo motiva el fin de agradar y de divertir, como enseña claramente Horacio en su Poética al decir: "Aut prodesse volunt, aut dilectare Poetae: Aut simul et iucunda, e idonea dicere vitae..." ["Los poetas quieren ser útiles o deleitar o decir a la vez cosas agradables y adecuadas a la vida", Epistola ad Pisones, vv. 333-4] también al Músico lo motiva idéntico fin, [consistente] en agradar y divertir, con acentos armónicos, los ánimos de los oyentes" (G. Zarlino, op. cit., 1558, parte III, cap. XXVI. Cito por E. Fubini, op. cit., p. 133). Humanismo, racionalismo, revolución científica son difusas tendencias de la época que permiten esta plena confianza apriorística en la univocidad de la relación entre las causas y los efectos. 
podían tardar mucho tiempo en rivalizar, ya que según el primero la música debía ser siempre fiel servidora o acompañante de la poesía, mientras que para el segundo, la música, aunque ayudada en un principio por el lenguaje verbal, aspiraría a crearse un propio lenguaje y llegar a ser, por consiguiente, autónoma. Más adelante estudiaremos las consecuencias de este cisma en la estética musical moderna.

En pocos años el melodrama evidenció que las directrices teóricas por las que había sido creado resultaban obsoletas, ya que la música era el elemento más reclamado tanto por parte del público como por parte de los cantantes ${ }^{9}$, de manera que en cuestión de pocos años logró zafarse del tedioso recitar cantando ${ }^{10}$ para recrearse con más libertad. Esta evolución hacia lo imaginativo debe considerarse normal en el contexto de la cultura italiana del Barroco, dominada por lo que a inicios del XVIII los árcades calificarían el cattivo gusto. El carácter heterogéneo del melodrama permitió desde muy pronto que en su seno confluyeran dos tendencias típicamente barrocas: de una parte, el exceso de ornamento y pompa en la música y demás artes auxiliares de la representación (decorado, vestuario, etc...), orientada a causar maravilla en el auditorio; de otra parte, la simplificación e irrelevancia progresivas del componente estrictamente literario, pues una trama compleja y un lenguaje exquisitamente poético no atraían al gran público ${ }^{11}$. Como consecuencia de todo ello, paulatinamente la

${ }^{9}$ El virtuosismo canoro de los solistas fue, en efecto, uno de los vicios más criticados tanto de la ópera barroca como de la post-metastasiana. Arteaga dedica un capítulo en sus Rivoluzioni (vol. II, cap. 3) a analizar este fenómeno y a proponer soluciones para su erradicación.

${ }^{10}$ Recitar cantando era el modo según el cual los humanistas de la Camerata del conde Bardi sostenían que debía expresarse el texto en la representación melodramática, y consistía en una declamación dotada de una tenue musicalidad, que era, presuntamente, como se desarrollaba originariamente el teatro griego, debido a su vez a la musicalidad intrínseca de la lengua griega, parcialmente perdida en las lenguas modernas a causa de la civilización. Es una idea que más adelante retomará Rousseau para defender el uso de la melodía en el melodrama en prejuicio de la armonía, considerada como un artificio. A. Solerti, en Le origini del melodramma (Turín, Bocca, 1903. Cito por E. Fubini, op. cit., p. 173) recoge testimonios de autores de melodramas del siglo XVII en los que se manifiesta de forma explícita la estrechez que el estilo recitativo suponía para la potencial espectacularidad que el melodrama portaba en sí, como se dejaba entrever a través de los todavía escasos momentos de musicalidad intensa que constituían las arias. Así, V. Giustiniani, en su Discorso sopra la musica dei suoi tempi (1628), afirmaba que el estilo recitativo "resulta tan tosco y carente de variedad de consonancias y ornamentos, que de no aminorar el aburrimiento que se siente [ante] la presencia de los recitadores, el auditorio abandonaría sus asientos y la estancia quedaría vacía por completo". También G. B. Doni, en el Trattato sulla musica scenica, decía que "este moderno estilo es defectuoso en muchas partes, las cuales no permiten que él ejerza aquellos efectos que en relación con la antigua música se lee que existan, ni que él cause a los oyentes aquél deleite que debería" (el subrayado es nuestro, para resaltar cómo bien pronto el carácter expresivo del melodrama adquirió prioridad sobre otros componentes, siempre partiendo de premisas aristotélico-horacianas).

${ }^{11}$ Los autores de melodramas habían aprendido del teatro nacional español que no había mejor regla para sus creaciones que la demanda del público y su respuesta: "Quest'opera sente delle opinioni moderne. Non è fatta al prescritto delle antiche regole; ma all'usanza spagnola rappresenta gl'anni et non le hore" afirmaba P. F. Cavalli, en la "Prefazione" a La Didone di Gio, Venecia, 1956 (cito por R. Tedeschi, op. cit., p. 1152). Sólo hasta la segunda mitad del siglo XVIII se concede validez desde el punto de vista estético al juicio crítico popular en la obra de arte. Este logro fue posible a partir de la idea sensista de la popularidad del conocimiento (expuesta originalmente por Locke en An Essay concerning Human Understanding, 1690) en virtud de la cual el conocimiento de la realidad no es fruto del raciocinio, sino de la experiencia sensible, que poseen todos los seres humanos. La realidad, por tanto, es accesible no sólo a los eruditos, sino a todos. J. B. Dubos (Réflexions critiques sur la poésie et la peinture, 1719) aplicó este principio a la experiencia artística, defendiendo que en el 
música pasaba de ser elemento ancilar del género a adquirir mayor protagonismo. Esta es la gran paradoja en la historia del melodrama: nació para reestablecer el dominio de la poesía sobre la música, y en dos siglos de historia no sólo perdió tal dominio, pasando a un segundo plano ${ }^{12}$, sino que además impulsó el desarrollo de la música instrumental o pura, como la llamaron los románticos. Estudiar este proceso de dos siglos de avatares sufridos por el melodrama, o mejor dicho, por la crítica del melodrama, desde 1590 hasta el Romanticismo, supone realizar un viaje por toda la cultura europea, desde la filosofía hasta la música, o desde la razón al sentimiento.

\section{Las polémicas en Francia en torno al melodrama.}

En la Francia de Luis XIV, la época de mayor esplendor cultural en la historia de aquel país, el siglo de Descartes, de Boileau y de Racine, por citar tan sólo tres ejemplos harto significativos, no podía pasar inadvertido un género nacido en Italia y que portaba la bandera de la restauración clasicista. Los postulados en los que se habían inspirado los inventores del melodrama encontraron fácil acomodo en el ambiente racionalista-clasicista francés del siglo XVII, por lo que también en este país se acogió y proliferó el nuevo género, con la diferencia de que en Francia no se desbordó, sino que se mantuvo siempre sujeto a las reglas ${ }^{13}$. Fue precisamente en Francia, y no en Italia, donde surgió el espíritu polemizador

terreno de lo bello y del sentimiento es donde más se justifica el apelo a la experiencia común. La divulgación de estas ideas en Italia corrió a cargo, principalmente, de Pietro Verri, quien afirmaba que es "buono il giudizio volgare nella musica, nella pittura, nella poesia drammatica, e in tutte le facoltà le quali hanno per fine primario il dilettare, giacchè gli uomini devono giudicare essi medesimi dalla impressione che sentono". (en Scritti vari, vol. II, cito por M. Fubini, "Arcadia e illuminismo", in Dal Muratori al Baretti. Studi sulla critica e sulla cultura del Settecento, pp. 340-1). Arteaga se hace eco de estas ideas en las Rivoluzioni, vol. II, cap. 3. Vid. también notas 18 y 21 de este artículo.

${ }^{12}$ La potencial espectacularidad del melodrama se basaba, como ya hemos dicho, en la música y no en el texto. Por este motivo, uno de los vicios más frecuentes a lo largo de su historia, y denunciados por la crítica que se remitía a la concepción original del género, es que el texto no pasa de ser un pretexto para la música, una simple estructura o cañamazo sobre la que asienta el espectáculo musical. Es interesante la analogía entre este fenómeno y el que movió a Goldoni a la reforma de la comedia, ya que hasta entonces la comedia del arte era "una especie de cañamazo genérico, de pauta indicativa, de red cuyos huecos debían ser rellenados por el particular ingenio de cada actor, a cuyo cargo quedaba suplir lo que en un texto dramático se le hubiera dado por escrito" (M. Carrera, "Introducción" a La posadera. Los afanes del veraneo. El abanico, Madrid, Cátedra, 1985, p. 12). La diferencia, sin embargo, como señala L. Bianconi, es que mientras en la comedia del arte la base es un espectáculo de naturaleza extra-literaria en el que, poco a poco, el literato conquista la centralidad del producto final, el teatro musical es inicialmente un espectáculo literario con otras artes ancilares, que paulatinamente arrinconan al texto. El melodrama es víctima de una tensión contradictoria: nace como producto esencialmente literario pero el público se aficiona a él con una percepción eminentemente aliteraria. ("Il Cinquecento e il Seicento", en AA. VV. "Parole e Musica", en A. Asor Rosa (ed.), Letteratura Italiana. Vol. VI: Teatro, musica, tradizione dei classici, Einaudi, Torino, 1986, pp. 226-437, p. 357).

${ }^{13}$ La disparidad de tendencias entre de los melodramas italiano y francés es perfectamente análoga a una serie de metáforas empleadas por T. Ceva para ilustrar el concurso entre el "yo" soñador y el "yo" razonador que, en opinión de este crítico, debe producirse en la creación poética: "L'un d'essi corre dietro a' fantasmi in cerca d'imagini e d'idee pellegrine, inoltrandosi a rintracciarle fin dentro agl'impossibili, traendone fuori Ninfe trasformate in allori, donne cangiate in sassi, Fauni, Arpie e cantatrici Sirene; l'altro le sceglie, le pulisce e trae lor di dosso la ruvida scorza, vestendole con le sembianze del vero. Quello corre a briglia sciolta, secondando il genio che lo trasporta, questo lo tiene in freno, prescrivendogli le misure del corso, e fermandolo dove bisogna. 
en torno al melodrama: acaso por un cierto afán de superioridad respecto a la cultura italiana, el melodrama francés fue pronto ensalzado como superior al italiano, si bien no faltaron voces en sentido contrario, también en Francia. La contraposición se estableció entre el melodrama francés, sobrio y sencillo, aristocrático y clasicista, hijo del racionalismo, y el italiano, que permitía una mayor libertad a la música, cuyos argumentos eran más acordes con el pujante mundo burgués, y que con el tiempo llegaría a conformar la variedad cómica, la opera buffa. Los más apasionados representantes de una y otra tendencia fueron François Raguenet (Paralléle des Italiens et des Français en ce qui regarde la musique et les opéras, 1702), a favor del melodrama italiano, y Lecerf de la Vievelle (Comparaison de la musique italienne et de la musique française, 1704, y Traité du bon goût) en defensa del melodrama francés. Es importante destacar que en esta polémica, como en general en sus sucesivas etapas, las diferencias están marcadas no tanto por el análisis que se hace de los hechos, sino en la forma en que éstos son valorados, estética y culturalmente. La valoración que hacen los defensores del melodrama italiano es, en última instancia, la de la corriente de pensamiento que aspira a deslindar el arte de la razón, como siglos antes había conseguido deslindar la ciencia de la teología, y alcanzará su eclosión definitiva en el Romanticismo, consolidando logros tales como la autonomía de la música respecto de la poesía.

Un segundo momento de estas polémicas se desarrolló entre las figuras de Jean Baptiste Lully, un florentino afincado en Francia desde joven, y al que se le considera como el verdadero creador de la ópera francesa, como defensor del clasicismo francés, y Jean Philippe Rameau, que, si bien surgido de la más pura tradición racionalista cartesiana, se erige, sin pretenderlo, en detractor de aquél, y por tanto, en defensor de la espontaneidad del melodrama italiano. A pesar de ello, y como se demostrará en el ulterior desarrollo de esta controversia, no es acertado encasillar el pensamiento musical de Rameau en un lado concreto de la tradición polemista del siglo, ya que sus ideas aspiraban a conformar un ideal de ópera por encima de las propuestas nacionales pero a la vez tomando aspectos de una y otra, que tardaría mucho tiempo en llevarse a cabo. Sólo Gluck, en la segunda mitad del siglo XVIII, conseguiría llevar a la práctica, si bien parcialmente, el ideal de la música concebida como lenguaje universal del sentimiento. Por un lado, la concepción del arte de Rameau estaba bien lejos de la superficialidad sentimentalista del gusto aristocrático rococó francés. Propugnó un arte menos formalista y más apasionado por parte del autor. Además, hizo ver una gran contradicción en la posición que hasta entonces el racionalismo había tomado respecto de la música: a ésta, como a todas las artes en general, no se le otorgaba más que una finalidad hedonista, la de procurar placer a los sentidos. Pero por otra parte, el racionalismo acogió y desarrolló (Descartes, Mersenne, Euler), con la mediación de Zarlino,

L'uno tutto intento alla novità, alla maraviglia e al diletto; l'altro tutto applicato all'utile, al verisimile e al decoro. Quello fa l'ufficio del vento che spinge; questo del timone che regola. Quello attende a colorire con presta mano, questo a finire con quiete e maturità di pensiero. Quello (per finirla) scappa, quanto può, in episodi e digressioni, saltando fuori dall'argomento; questo vel rimette dentro di continuo ritraendolo dalla fuga" (Memorie d'alcune virtù del Signor Conte Francesco de Lemene con alcune riflessioni su le poesie, Milano, 1718. Cito por G. Compagnino - G. Savoca, Dalla vecchia Italia alla cultura europea del Settecento, en "Letteratura italiana Laterza", vol. VI, Il Settecento, tomo 32, Bari, Laterza, 1979, p. 184). 
la tradición pitagórica de la música ${ }^{14}$; reconocía así, implícitamente, que la música, además de ser placentera, es un hecho racional e inteligible, una ciencia ${ }^{15}$. Con su posición, Rameau no despreció a la melodía frente a la armonía, sino simplemente otorgó a ésta el fundamento racional sobre el que se construyen los demás elementos de la música, incluida la melodía. De esta forma, desautorizó el creciente abuso que en Italia se venía dando del melodismo irracional, siendo calificado por ello de árido intelectualista ${ }^{16}$. Como vemos,

14 A partir de los mitos musicales más importantes en la antigua Grecia, que son el de Orfeo y Dionisio, se difundió la idea de que el placer producido por la música era la manifestación de un poder mágico que ésta poseía; un poder que, siendo capaz de alterar las leyes de la naturaleza - por ejemplo, conciliando entidades opuestas, como la vida y la muerte (son los "milagros", según la tradición cristiana) - hubo de ser necesariamente asociado a un origen divino (Apolo, según Pseudo-Plutarco, fue el inventor de la flauta y la lira). Esta capacidad para conciliar contrarios fue denominada armonía por la escuela pitagórica, y se podía producir tanto en el universo como en el alma. Pero la armonía es un concepto abstracto e informe, que sólo a través del número puede hacerse inteligible. Según la tradición, Pitágoras halló en las relaciones entre los sonidos el modelo perfecto de armonía que existe entre los astros, e incluso llegó a afirmar que los astros producen una música. Análogamente, la armonía del alma, al poseer la misma naturaleza, puede ser reestablecida por la música. Mutatis mutandis, el Cristianismo, desde los Padres de la Iglesia, atribuyó a la música los mismos poderes que le habían atribuido los pitagóricos. De Orfeo se pasó al personaje bíblico David. San Agustín acentuó el carácter de ciencia que poseía la música en su tratado De Musica ("Musica est ciencia bene modulandi": la música es la ciencia de medir bien). Con ello puso el énfasis en que la música atañe a la razón y no a los sentidos: los tañedores de instrumentos poseen un conocimiento musical inferior al de los teóricos que conocen su fundamento matemático. Un siglo más tarde, Boecio (en De institutione musica) también se basó en la tradición pitagórica al subdividir la música en tres géneros, mundana, humana e instrumental. A partir del año 1000, que es cuando empiezan a crearse las dos mayores aportaciones del Medioevo a la historia de la música, el contrapunto y la polifonía, se hace cada vez más necesario ir dejando de lado los dos primeros géneros boecianos para insistir en la musica instrumental, que es la que realmente se oye. Era el comienzo de un largo proceso histórico que tiende a suprimir los supuestos orígenes divino y místico de la música para considerarla como exclusivo fruto de la razón y las matemáticas. Zarlino y Rameau representan, precisamente, las dos etapas finales de dicho proceso. Pero la concepción pitagórica de la música no acaba aquí: en tanto que constituye el filón más importante del pensamiento musical occidental, es enormemente complejo, y ya en Grecia dio pie a distintos desarrollos, según se pusiera el énfasis en su componente moralista, matemático o metafísico. Zarlino y Rameau son herederos de la orientación matemática. Los humanistas de la Camerata lo son de la moralista (Cfr. E. Fubini, op. cit., caps. I a IX).

15 J. Ph. Rameau, Traité de l'harmonie réduit à son principe naturel, Paris, 1722. (Cito por J. Neibauer, op. cit., p. 120). Esta puente que Rameau tiende entre el arte y la razón participa de la misma idea que inspiraría, pocos años después, a Baumgarten para tender, igualmente, un nexo entre lo lógico y lo sensible, entre las ideas claras y distintas, propias del mundo intelectual y lógico, expresable lingüísticamente, y las ideas oscuras y confusas del mundo sensible. Baumgarten sostuvo que el filósofo también debe ocuparse del conocimiento sensible, aunque éste sea considerado inferior, ya que contienen una lógica particular, y por tanto es un conocimiento susceptible de ser estudiado a través de una ciencia (Baumgarten llamó a la ciencia de la perfección del conocimiento sensible, precisamente, Estética). De la misma manera, Rameau asoció el placer que produce la música con la lógica que rige los sonidos, al entender que dicha lógica, la armonía, no sólo no está reñida, sino que conduce a la perfección del conocimiento sensible musical, y por tanto, del placer musical. Se trata, en definitiva, de dos pensadores que, partiendo de una posición netamente racionalista (y sin pretender abandonarla) muestran una cierta inquietud e interés por el mundo de lo sensible, que desde la escuela empirista estaba adquiriendo una dimensión gnoseológica cada vez más relevante.

16 "...ese célebre músico que nos liberó del canto llano de Lulli que salmodiábamos desde hacía más de un siglo; que ha escrito tantas visiones ininteligibles y verdades apocalípticas sobre la teoría de la música de las que ni él ni nadie comprendió nunca nada, y de quien poseemos cierto número de óperas en las que hay armonía, fragmentos de cantos, ideas deshilvanadas, estruendo, vuelos, triunfos, lanzas, glorias, murmullos, victorias hasta más no poder; aires bailables que durarán eternamente y quien, tras haber enterrado al Fiorentino [Lully], será él mismo enterrado por los virtuosos italianos, cosa que él presentía,..." (D. Diderot, Le neveu de Rameau, 
tampoco se le puede considerar un defensor a ultranza del melodrama italiano. En realidad, el pensamiento de Rameau, al igual que el de Vico, no fue asimilado en su totalidad por sus contemporáneos, y sólo el Romanticismo supo y pudo valorarlo.

El creciente éxito de la modalidad cómica en el melodrama italiano, la ópera bufa, empezó a tener repercusiones entre los críticos franceses hacia 1750, renovando así con posiciones evolucionadas las polémicas anteriores. De una parte se sitúan los defensores del melodrama clásico francés o antibufonistas, cuyos modelos eran Lully y Rameau (como ya dijimos antes, las ideas de Rameau podían interpretarse también como contrarias al melodismo del que hacía gala la ópera italiana, implicando indirectamente el apoyo a la más pura tragedia clásica francesa). De otra parte, los bufonistas, partidarios de la frescura y espontaneidad del melodrama bufo italiano, bando en el que se alinean la mayoría de los enciclopedistas, como Diderot ("los poetas son como los locos en la corte de los reyes: dicen lo que quieren porque se les desprecia"), y que partiendo de un rechazo de la idea del arte como un juego inocente, típica del rococó, teorizaron una idea más profunda del mismo como expresión apasionada de los sentimientos del autor ${ }^{17}$. La ópera bufa se erige así como la impulsora de la estética del sentimiento en el melodrama, al tiempo que evidencia el camino equivocado, en algunos aspectos, de las propuestas de reforma del género en su modalidad seria, tendentes a aceptar la importancia de la música como un mal inevitable pero empeñados en mantenerla sometida a la poesía. La ópera bufa, por su forma y contenido, no teniendo aspiraciones aristocráticas, sorteó las reglas clasicistas y la crítica más retrógrada que desde principios de siglo se ensañó con el melodrama serio, por considerar que éste aspiraba a suplantar a la tragedia clásica (más adelante hablaremos detalladamente de la discordia entre el melodrama y las reglas). La ópera bufa, en definitiva, fue simplemente ignorada por los literatos neoclasicistas, evitó caer en un rígido formalismo y logró conectar con el gusto burgués e ilustrado, pues mostraba personajes y peripecias del mundo cotidiano, al estilo de las novelas de Richardson y la comédie larmoyante francesa. Y cuando dejó de ser ignorada por la crítica, fue para ser ensalzada por su mayor vitalidad respecto a la ópera seria, por su "naturalidad" y "verosimilitud". Para entonces las ideas estéticas habían cambiado, tanto en lo referente al lenguaje poético como

escrita en 1761, pero publicada póstuma en 1823. El fragmento está tomado de la edición en español, El sobrino de Rameau, a cargo de Carmen Roig, Madrid, Cátedra, 1985, pp. 70-1)

17 Son los inicios de las teorías expresivas de la obra de arte, que partiendo de la teoría pragmática y su énfasis en el efecto producido por la obra en el receptor, desplaza paulatinamente dicho interés hacia el proceso de producción de la obra, y por tanto, hacia la psicología del autor (vid. M. H. Abrams, El espejo y la lámpara. Teoría romántica y tradición crítica acerca del hecho literiario, Buenos Aires, Nova, s.a., pp. 28-45). En Italia, la evolución de una poesía que por su preciosismo formal y su musicalidad prendía fácilmente en el público, a una poesía de mayor contenido y sentimiento, constituye la línea medular en el paso de la poesía arcádica y rococó, a la poesía ilustrada neoclásica de la segunda mitad del siglo, y cuyo representantes más conspicuos son los críticos que conforman el grupo del Caffè y su lema "Cose, non parole" y la obra poética y crítica de Parini. (Vid. G. Gronda, "Introduzione" a Poesia italiana. Il Settecento, Milano, Garzanti, 1978, p. XVIII. También M. Fubini, op. cit.). La expresividad en el arte, y en concreto, en la literatura, está íntimamente relacionada con el desarrollo de las nuevas ideas acerca de la tragedia y del lenguaje poético. Cfr. notas 18 y 21 de este artículo. 
al fundamento de la tragedia ${ }^{18}$, de manera que gozó de legitimidad para desplegar toda la fantasía y el esplendor que el melodrama guardaba en potencia: la música fue reconocida como protagonista indiscutible del género y a ella se acopla la poesía, dando como resultado un espectáculo grandioso. Poesía y música dejan de estar, más que nunca, separadas. Los términos de la polémica se han invertido desde sus comienzos, cuando Lecerf acusaba al melodrama italiano de artificioso y barroco, frente a la sencillez y linealidad del francés. Ahora es el melodrama francés el que recibe la acusación de poco natural e intelectualista, mientras el italiano representa la frescura y espontaneidad melódicas. Por otra parte, el impasse al que se vió abocado el melodrama serio no debe inducirnos a pensar en un estado terminal del mismo, ni en la vanidad absoluta de los esfuerzos reformadores de los literatos de la segunda mitad del siglo, que más adelante analizaremos. Ya a partir de los años 70 el melodrama serio empieza a dar muestras de regeneración, aprendiendo del bufo elementos técnicos ${ }^{19}$ que lo llevarán, gradualmente, sobre el mismo camino. La ópera de Mozart es la culminación de este proceso en la ópera seria.

Hemos aludido antes a las nuevas ideas en torno al lenguaje poético. La cuestión merece ser tratada, aunque sólo sea brevemente, ya que el éxito de la ópera bufa fue en gran parte debido a las ideas en boga de la época acerca de la fuerza poética del lenguaje primitivo y espontáneo, que constituyó un tópico en la literatura filosófica de la segunda mitad del XVIII, a partir del anticartesianismo de Vico ${ }^{20}$ y su Scienza nuova (1725), pero difundido con más fortuna por Rousseau. Éste, partiendo de su teoría acerca del origen del lenguaje y su corrupción moderna ("el estudio de la filosofía y el progreso del razonamiento, tras haber perfeccionado la gramática, privaron a la lengua de ese tono vivo y apasionado que la había

\footnotetext{
${ }^{18} \mathrm{La}$ aceptación, desde el punto de vista filosófico, de que la literatura represente personajes y situaciones de la vida cotidiana tiene lugar en el marco del componente sensista del pensamiento ilustrado. Lessing, en Hamburgische Dramaturgie, partiendo de la urgencia de dotar a Alemania de una literatura autóctona, libre de la imitación de la francesa, propuso explícitamente que la tragedia debía retratar personajes plebeyos, con los que el pueblo se sintiera identificado y llegara a compadecerse con sus dramas íntimos y privados. Sólo así llegará una auténtica catarsis. La tragedia, por tanto, también se puede producir en la vida cotidiana. (Vid. J. L. Villacañas, "Lessing y la construcción de la Ilustración alemana", en La quiebra de la razón ilustrada. Idealismo y Romanticismo, Madrid, Cincel, 1988, pp. 32-51). Estas ideas, que tomaban muchos elementos del teatro de Shakespeare, encontraron su plasmación práctica en el llamado drama burgués, y del que Diderot, en sus primeros escritos, fue un apasionado defensor, frente a la tragedia clásica francesa, que él consideraba forzada e inverosímil (vid. R. Wellek, "Diderot", en Historia de la crítica moderna (1750-1950), vol. I: "La segunda mitad del siglo XVIII", Madrid, Gredos, 1969, pp. 61-77). Arteaga trata esta cuestión en las Rivoluzioni, vol. II, cap. IV.

19 Se encuentran enumerados y analizados en Di Benedetto, "Il Settecento e l'Ottocento", en AA. VV. "Parole e Musica" (cit.), pp. 393 y ss.

20 "La naturaleza es obra exclusiva de Dios, sin la intervención del hombre; por lo tanto, sólo Dios puede tener un conocimiento adecuado y pleno de la naturaleza. Pero la sociedad humana, las leyes humanas, el lenguaje y la literatura son todos obra del hombre. Por lo tanto, el hombre puede verdaderamente entenderlos, así como entender los principios de su desarrollo. Aquí tenemos una auténtica inversión de la actitud cartesiana. Las ciencias que Descartes subestimaba en beneficio de las físicas se encuentran ahora en una posición de superioridad" (F. Copleston, "Bossuet y Vico", en Historia de la Filosofía, Vol. VI: "De Wolff a Kant", Barcelona, Ariel, 1991, 2a ed., p. 155)
} 
hecho al principio tan melodiosa") ${ }^{21}$ llegó a la idea de que la melodía representa el estado más puro y primitivo de la expresión musical del hombre, mientras que considera la armonía como una invención gótica y bárbara. El lenguaje poético primitivo también encontró apoyo desde el sensismo de Locke, que dotó al arte de una capacidad que el racionalismo le había negado: dado que el arte es capaz de crear sensaciones, puede, al igual que la experiencia directa aunque de un modo más atenuado, dar al alma los estímulos de placer y dolor. Estas ideas, por mediación de Condillac, fueron acogidas y divulgadas en Italia por C. Beccaria (Ricerche intorno alla natura dello stile, 1770), G. Parini (Discorso sulla poesia, 1761) y F. M. Pagano (Del gusto delle belle arti y Discorso sull'origine e natura della poesia). Beccaria considera el estilo como el instrumento con el cual el escritor busca las palabras precisas para estimular el placer y el dolor en el alma. Dado que la sensación artística es siempre menos intensa que la sensación real pero debe acercarse a ella, las palabras de la poesía "sono tanto più energiche e poetiche quanto conservano più fresca la traccia del linguaggio primitivo ordinario"22. La poesía, por tanto, debe esforzarse por rescatar el sentido originario de las palabras. Esta posición fue llevada aún más lejos por Diderot $^{23}$.

El tercer momento de las polémicas en torno al melodrama en Francia, cuyos máximos representantes son los músicos Gluck y Piccini, carece del vigor de las dos anteriores, en parte debido a que en ella la figura del primero eclipsa al segundo, y en parte porque se confunde en medio de las propuestas de reforma llevadas a cabo por los literatos italianos. Será analizada en el siguiente punto.

\footnotetext{
${ }^{21}$ Essai sur l'origine des langues, 1749 (cap. XIX. Cito por trad. española de M. Armiño, Ensayo sobre el origen de las lenguas, Madrid, Akal, 1980, p. 107). Se difunde así otro tópico, el de la oposición entre poesía primitiva o natural y poesía moderna o artística, englobando la primera toda aquella poesía que no perteneciera a la tradición latino-francesa: la Biblia, Homero, Ossian, la épica caballeresca, etc.. y que muchos críticos empezaban a considerar como el ambiente poético más imaginativo, debido a una presunta unión original de la poesía con la danza y el canto. Otra presunción era que el lenguaje primitivo es, por naturaleza, poético y metafórico, como sostiene J. Brown en Dissertation on the Rise, Union and Power, the Progressions, Separations and Corruptions of Poetry and Music (1763. Cito por Wellek, op. cit., p. 163). Arteaga, en las Rivoluzioni (vol. I, cap. 1) se hace eco de estas ideas al hacer un elogio de la metáfora. Por otra parte, y acentuando el filón patético y siniestro contenido en la poesía primitiva, especialmente la de Ossian, E. Burke, en Philosophical Enquiry into the Origin of our Ideas of the Sublime and Beautiful, 1756, desarrolló a partir de la categoría longiniana de lo sublime toda una estética de gran fortuna en la poesía prerromántica y romántica. Pero esta compleja cuestión nos llevaría demasiado lejos (Véase al respecto R. Assunto, "Origen inglés de la estética romántica", en Naturaleza y razón en la estética del setecientos, Madrid, Visor, 1989).

22 C. Beccaria, op. cit.. Cito por G. Petronio, L'attività letteraria in Italia, Firenze, Palumbo, 1988, p. 406. Vid. también M. Fubini, op. cit., pp. 340-1 y pp. 327-330.

23 "Hay más ardor de inspiración en los pueblos bárbaros que en los cultos, más ardor en los hebreos que en los griegos, más ardor en los griegos que en los romanos, más ardor en los romanos que en los italianos y franceses, más ardor en los ingleses que en estos últimos. Por todas partes decae el ardor y la poesía a medida que va progresando el espíritu filosófico" (Oeuvres complètes de Diderot, ed. Assézat-Tourneux, s.d. Cito por R. Wellek, op. cit., p. 65). Cfr. también el artículo "Goût" de la Encyclopédie.
} 


\section{La reforma del melodrama en el Settecento italiano.}

Volviendo un poco atrás en el tiempo, para conocer la génesis de la aportación italiana en el siglo XVIII a la crítica del melodrama, recordemos que a lo largo de la segunda mitad del siglo XVII tuvo lugar el fin de la presencia española en Italia y el comienzo de la francesa. Las consecuencias culturales de este hecho son, como se puede suponer, inmensas: la gradual sustitución de una cultura contrarreformista, retrógrada en muchos aspectos, por una cultura pujante y renovada que venía de la Francia de Luis XIV. El afrancesamiento progresivo de la cultura italiana a finales del siglo XVII es imparable ${ }^{24}$, como ocurriría en España a partir de 1713, a raíz de la instauración de la dinastía borbónica: la sociedad se impregna de racionalismo y clasicismo, se instaura en el arte el gusto rococó, y en la literatura, el gusto arcádico, que se manifiesta en un obsesivo afán por eliminar el cattivo gusto que sin titubeos se asociaba a la presencia española. La poética aristotélica considerada oficial pasó a ser la interpretada por el gran preceptista Boileau en 1674, y en ella se inspiraron los principales autores de poéticas neoclásicas, en Italia (Gravina, Muratori) y en España (Luzán). En virtud de estas reglas, no debía haber más que dos formas de teatro, la tragedia y la comedia; para la primera los modelos eran Corneille y Racine, y para la segunda, Moliére. No había lugar, bajo esta óptica, para un género híbrido y moderno como el melodrama (como tampoco lo habría para la comédie larmoyante), y en efecto, los árcades más puristas abogaron sin más por la desaparición del mismo, al considerarlo una pseudotragedia que violaba las reglas aristotélicas ${ }^{25}$. Pero pronto cuajaron esfuerzos en clave

\footnotetext{
24 No obstante lo dicho, no es correcto asociar unívocamente el dominio político de una nación a su influencia cultural sobre las demás. El elemento primordial que dota de una base sólida a la influencia cultural de una nación sobre otra, como dijera Croce, es la filosofía, pues "la potenza di una cultura ha il suo fulcro e insieme il suo strumento nel pensiero e nella filosofia" (en A. Croce, "Relazioni della letteratura italiana con la letteratura spagnuola", Viscardi, 1948, s.l., p. 110. Cito por C. Guillén, Entre lo uno y lo diverso. Introducción a la literatura comparada, Barcelona, Crítica, 1985, p. 309). De ser cierta esta teoría, se explica el escaso arraigo de la influencia cultural española en Italia a lo largo del XVII, muy al contrario de lo que sucedería con la irrupción francesa.

25 Muratori, en Della perfetta poesia italiana (1703) (lib. III, 4-6) proclama su rechazo al género melodramático, por considerarlo causante de la decadencia del teatro trágico en Italia. La principal acusación formulada contra el melodrama para abolirlo era el de la inverosimilitud: "È egli mai verosimile fra le genti che una persona in collera, piena di dolore e d'affanno, o narrante seriamente e davvero i suoi negozi, possa cantare? E se ciò non è verosimile fra le genti, come il sarà nella scena, ove s'ha da imitare, il più che sia possibile, la natura e la varietà delle azioni e de'costumi dell'uomo?". Arteaga, en las Rivoluzioni, (vol. I, cap. 1, pp. 30-1) responde a estas acusaciones de Muratori. De forma más explícita fue programada una reforma de la tragedia por Calepio, en Paragone della poesia tragica d'Italia con quella di Francia (1732). Más autores en esta línea fueron Gravina, Maffei, Baretti, Milizia, etc... (vid. G. Nicastro, Metastasio e il teatro del primo Settecento, en "Letteratura italiana Laterza", vol. VI, Il Settecento, tomo 33, Bari, Laterza, 1974, pp. 11-2, E. Fubini, op. cit., p. 176, y R. Tedeschi, op. cit., p. 1154). La opinión de Gravina respecto al melodrama podemos calificarla de intermedia, ya que acepta y defiende el recitativo, mientras que condena el aria (vid. G. Della Volpe, Historia del gusto, Madrid, Visor, 1987, p. 52). A pesar de estas explícitas afirmaciones contrarias al género melodramático, en sus epistolarios privados muchos de estos árcades no podían ocultar hasta qué punto llega su fascinación ante la grandiosidad del este espectáculo, y como italianos, dejan escapar comentarios de orgullo y de defensa del melodrama italiano frente al francés. Di Benedetto (op. cit., p. 366 y ss.) interpreta esta actitud contradictoria de forma positiva: la Arcadia fue mucho más que un empeño alocado por desterrar el cattivo gusto de la literatura italiana; era un compromiso serio y responsable de modernización de la cultura
} 
arcádica tendentes a contrarrestar esta opinión, principalmente a cargo de P. J. Martello26, A. Planelli ${ }^{27}$, B. Marcelo ${ }^{28}$, A. Zeno ${ }^{29}$, y de forma definitiva, de P. Metastasio ${ }^{30}$, autores a

italiana para acercarla a Europa pero sin desdeñar los elementos nacionales y autóctonos de Italia, es decir, buscando crear una conciencia de "cultura nacional".

${ }^{26}$ Este autor fue el primero de los árcades que se pronunció abiertamente a favor del melodrama, y publicó en 1714 una explícita conciliación de la poética aristotélica y este género, titulada "Della tragedia antica e moderna", que simula un diálogo con Aristóteles en el que éste dicta una "poética del melodrama" (Vid. Di Benedetto, op. cit., p. 381-4.).

27 Trattato dell'opera in musica, Nápoles, 1721: "Le sue osservazioni circa le belle arti in genere, e circa la musica, e direzione del teatro in particolare sono assai giudiziose, e proficue, e da pertutto respirano l'onestà, la decenza, e il buon gusto. Nientedimeno senza derogar al merito d'un libro, ch'io credo il migliore di quanti siano usciti fin'ora alla luce massimamente nella parte didascalica, parmi, che i pensieri dell'autore intorno alla parte poetica del dramma non abbiano nè la giustezza nè la profondità che campeggiano in altri luoghi: mi sembra, che abbia poco felicemente indagati i distintivi fra l'Opera e la tragedia, e che non venga dato gran luogo alla critica e molto meno alla storia, ond'è, che molto ei ci lascia a desiderare sì nell'una che nell'altra" (E. Arteaga, Rivoluzioni, vol. I, cap. 1, pp. 24-5).

${ }^{28}$ La aportación de B. Marcelo a la reforma del melodrama se condensa en su célebre obra Teatro alla moda (1721), sátira de los vicios del melodrama e impulsora de un abundante elenco de obras satíricas con la misma intención de denunciar la sumisión del libretista a los gustos del músico y del cantante. No fue, sin embargo, la primera, que fue obra de Francesco F. Frugoni, con su drama musical L'innocenza riconosciuta. Estas sátiras se encuentran en los más variados géneros, incluido el mismo melodrama: la Dirindina de Gigli, el Impresario delle Canarie de Metastasio, un intermezzo de la Didone abbandonata; también Prima la musica, poi le parole de Casti. Goldoni, en sus Mémoires ensaya también esta modalidad de crítica, así como Arteaga, en las Rivoluzioni (vol. II, pp. 187-195), y Calzabigi con L'opera seria. Anelli, ya en el 800, es el epígono de este filón, más próximo a la moralística que a la sátira. Di Benedetto (op. cit., p. 369) interpreta la proliferación de este filón en la misma línea que interpreta los comentarios favorables que en privado los árcades daban del melodrama (vid. n. 25): refleja un compromiso por parte de la Arcadia de salvar el melodrama como expresión de la cultura nacional, despojándolo de sus elementos negativos.

29 Zeno llevó a cabo la ardua tarea de conciliar el género melodramático con la poética aristotélica. En ello se adelantó a Metastasio, que en este aspecto no fue más allá de los logros alcanzados por su antecesor. Sin embargo, la crítica reciente cuestiona el carácter efectivamente reformador de la obra de Zeno, integrándolo simplemente en una tendencia evolutiva general a los libretistas de la época, tales como Silvani, Stampiglia, David, Salvi o Frigimelica Roberti, que preparan el camino para la gran reforma metastasiana (cfr. G. Nicastro, op. cit., pp. 65-8) Dicha tendencia se manifiesta en la "simplificazione delle trame, la soppressione delle scene comiche, la netta distinzione tra recitativo e aria, lo sfoltimento delle scene e la minor frequenza delle arie, la cura per una loro più funzionale distribuzione e per un loro più omogeneo assetto metrico, il ricorso alla tecnica della liaison des scènes per uno svolgimento più ordinato e coerente dell'azione drammatica" (Di Benedetto, op. cit., p. 384).

30 En el melodrama metastasiano coexisten dos factores que se influyen recíprocamente, hasta el punto que es difícil establecer cuál de los dos da pie al otro. Tales factores son la estructura de la estrofa y un definitivo asentamiento en la tonalidad de la música. Sus conocimientos de música eran vastos, y ello le permitió manejarla y someterla a la poesía, pues Metastasio mantuvo siempre una concepción logocéntrica del melodrama: "Affermò sempre l'indipendenza della sua poesia dalla musica: quest'ultima doveva servire come commento sonoro da non sovrapporsi alla primitiva espressione. Circa la funzione dei due elementi del melodramma il Metastasio pensava che il recitativo dovesse imitare col canto le modificazioni del parlare naturale e le ariette dovessero costituirne gli sbocchi finali" (G. Nicastro, op. cit., p. 73). También la poesía cede terreno, al ser escasos tanto el vocabulario como las formas lingüísticas en general. Baretti resaltó este hecho como mérito del autor. Sin embargo, la evolución posterior del lenguaje musical en la segunda mitad del 700 rompe con este frágil equilibrio alcanzado por Metastasio entre poesía y música, de manera que algunos críticos hablan de un "fracaso de la reforma metastasiana". Ya los músicos contemporáneos a él pusieron el énfasis en sus arias, abusando de la legitimidad que Metastasio concedió al virtuosismo canoro, considerado un defecto de la ópera barroca y que sin embargo él supo integrar con naturalidad en el conjunto del espectáculo. En cuanto a la temática de sus obras, es importante la sutil identificación entre lo ficticio y lo real, que alguna crítica interpreta 
los que podemos colocar la etiqueta historiográfica de fundadores de la reforma del melodrama: una reforma que partiendo del reconocimiento de la degradación del género a lo largo del siglo anterior, pero también considerando que se trataba del espectáculo más popular, optaba por acomodarlo al clasicismo arcádico, podándolo de sus excesos barrocos. Este programa conciliador presuponía, obviamente, una concepción más flexible y abierta de las reglas poéticas ${ }^{31}$, al tiempo que exigía de la creación melodramática una mayor seriedad y coherencia, empezando por dotar a la poesía del protagonismo perdido, aún a riesgo de sacrificar parcialmente la fuerza espectacular del género. Con la obra crítica y creativa de Metastasio Italia arrebata la iniciativa a Francia en la crítica del melodrama, sustituyendo el espíritu primordialmente polemizador de los franceses por una inquietud más reformadora y humanista, sólidamente asentada sobre premisas netamente neoclásicas.

Esta iniciativa italiana de reforma del melodrama en la primera mitad del siglo tiene su continuación en una serie de importantes aportaciones publicadas a partir de 1755 , caracterizadas todas por discurrir sobre una vía intermedia entre las posiciones defendidas por los críticos franceses, ya fueran clasicistas o enciclopedistas. Tal vía intermedia, o mejor dicho, complementaria, es la genuina heredera de la tradición humanista inaugurada por la Camerata de los Bardi, es decir, una línea fundamentalmente de literatos, y no de músicos, como Zarlino. Aunque los miembros de la Camerata se sirvieron de algunas ideas de Zarlino, como las que provocaron la decadencia del contrapunto, no compartían con éste la necesidad de dotar a la música de una racionalidad que le permitiera en el futuro crear su propio lenguaje y desligarse de la poesía. Era, en definitiva, una tendencia más preocupada de la suerte de lo literario que de lo musical en la praxis del melodrama. La evolución del melodrama a lo largo del siglo XVII, y su favorecimiento implícito de la autonomía musical, puso de manifiesto las diferencias entre ambas concepciones. Se hace necesario, por tanto, dar un salto atrás en la historia de la estética musical para conocer el origen de esta segunda línea humanista que se empecina en impedir la intimidación de la poesía por parte de la música en el seno del melodrama.

como un puente que establece Metastasio entre el formalismo rococó-aristocrático y el sentimentalismo característico del drama burgués. Vid. F. Mollia, "Introduzione" a P. Metastasio, Opere, Milano, Garzanti, 1979, pp. VII-XXVII, G. Nicastro, op. cit., pp. 69 y ss., pp. 107 y ss., Di Benedetto, op. cit., p. 385 y ss., G. Petronio, op. cit., pp. 374-5, G. Della Volpe, op. cit., p. 52.

31 Frente a una interpretación excesivamente rígida de las reglas aristotélicas respecto a la tragedia, la clave metastasiana para salvar al melodrama está expresada en su Estratto dell'arte poetica di Aristotile (en Metastasio, Opere, Milano, Garzanti, 1979, pp. 237-242), donde vierte consideraciones acerca de la unidad de lugar, la catarsis y el concepto de imitación, que a diferencia de la copia, no pretende asombrar al público por el mayor parecido posible con el original, sino causar admiración por la victoria que el artista consigue en doblegar los medios de su arte (ya sea el mármol, el color o las palabras) al objeto imitado. Esto es "imitar il vero col falso" (vid. G. Nicastro, op. cit., pp. 99-103). Idéntica distinción es la que expresa Arteaga en $L a$ belleza ideal: "El imitador se propone imitar su original no con una semejanza absoluta, sino con la semejanza de que es capaz la materia o instrumento en que trabaja. Por eso lleva la imitación hasta donde llega la flexibilidad del instrumento; y cuando éste por su naturaleza no alcanza a más, no procura, como el copista, ocultarle, antes bien le manifiesta, para que, observándose la dificultad de la imitación y la indocilidad del remedio, se admire más y más el talento de quien pudo llegar a tanto" (ed. a cargo de M. Batllori, Madrid, Espasa-Calpe, 1972, p. 12). 
Para ello, tenemos que volver sobre la concepción pitagórica de la música, la cual, como ya dijimos anteriormente ${ }^{32}$, ya en Grecia dio pie a distintos enfoques, según se acentuara el aspecto moralista, el matemático o el metafísico. El metafísico fue suprimido desde el racionalismo y sólo con el Romanticismo fue rescatado ${ }^{33}$. El matemático es el que conforman, en la época moderna, Zarlino y Rameau. El moralista fue desarrollado por Damón, filósofo y músico griego (siglo $\mathrm{V}$ a. de C.), quien partía del principio de que tanto el sonido como el alma son entes en movimiento, de manera que el sonido puede imitar a los movimientos del alma, y puede restablecer su armonía en caso de que la haya perdido, pero también hacérsela perder si se la disocia del canto. Mientras la música no pase de ser acompañamiento de la poesía, su valor moral está garantizado, ya que impide que la música por sí sola divague y incite a la corrupción moral. De este principio moralista se sirvieron los humanistas de la Camerata, si bien con una intención meramente filológica y literaria, para asociar indisolublemente la música con la palabra, y de ahí el estilo de recitar cantando, o sea, imitar col canto chi parla. Los humanistas, en definitiva, dieron prevalencia a la "palabra".

Ahora podemos entender mejor el punto de vista respecto de la música común a los literatos reformistas del melodrama en la segunda mitad del XVIII. Todos parten de la negación rotunda de la autonomía de la música respecto de la poesía, al tiempo que hacen esfuerzos por asumir y aceptar el creciente dinamismo y vivacidad de la música, reconociendo que su evolución desde Metastasio hasta entonces ha roto el frágil equilibrio que este autor había logrado en sus libretos, y proponen la búsqueda de nuevas fórmulas para que la poesía ceda más terreno a la música sin que por ello pierda deje de ser el componente central del melodrama. Los autores que conforman este grupo y sus obras relativas al melodrama son los siguientes: F. Algarotti, Saggio sopra l'opera in musica $(1755)^{34}, \mathrm{R}$. de'

\footnotetext{
32 Vid. nota 14.

33 Los románticos, efectivamente, rescatan el poder místico y mágico que los racionalistas creyeron haber borrado para siempre de la expresión musical. Léanse a modo de ejemplo estas afirmaciones de Wackenroder (1773-1798): "Ningún otro arte, a excepción de la música, dispone de una materia prima que esté, ya de por sí, tan llena de espíritu celestial" (Fantasía en torno al arte de un monje amante del arte. Cito por E. Fubini, op. cit., p. 260) o "la música describe los sentimientos humanos de manera sobrehumana [...], puesto que habla un lenguaje que nosotros no conocemos en la vida corriente, acerca del cual no sabemos ni dónde ni cómo lo hayamos aprendido, pudiéndose admitir tan sólo como lenguaje propio de los ángeles" (de Las maravillas del arte musical. Cito por E. Fubini, ibid.). El tópico de la inefabilidad del efecto musical puro, sin acompañamiento de la palabra, se renovó con vigor entre los románticos: "Alla radicata convinzione umanistica, che la musica dovesse essere giudicata solo in funzione della sua subalternità alla poesia, si aggiungevano ora, nella seconda metà del 700, le richieste della 'nuova sensibilità', il bisogno di commozione, la prepotente e diffusa 'voglia di lacrime': tutte esigenze che la musica poteva soddisfare solo spogliandosi di qualsiasi abito scientifico e dichiarando guerra al freddo e astruso contrappunto" (Di Benedetto, op. cit., pp. 370 y ss). La música se erigió entre los románticos como el ideal de expresión al que la poesía debía tender: la poesía, en definitiva, no debe imitar a la pintura (ut pictura poesis) sino a la música (ut musica poesis). Vid. M. H. Abrams, op. cit., pp. 134144.

${ }^{34}$ El contenido de este breve ensayo es básicamente coincidente con el de las Rivoluzioni de Arteaga. Algarotti adopta ante el melodrama una actitud típicamente literaria y logocéntrica: "l'argomento o il libretto contiene in sé [...], ogni parte, ogni bellezza dell'opera, e da esso ne dipende principalmente la riuscita" (en Opere di Francesco Algarotti e di Saverio Bettinelli, "La letteratura italiana. Storia e testi", vol. 46: Illuministi italiani, tomo 2, Milano-Napoli, Ricciardi, 1960, p. 479). El ensayo de Algarotti, con todo, tiene una intención meramente
} 
Calzabigi, "Dissertazione" a las Opere de Metastasio (1755) ${ }^{35}$ y, junto a C. W. Gluck, la "Prefazione" a la ópera Alceste $(1767)^{36}$, S. Mattei, La filosofia della musica o sia la riforma del teatro $(1781)^{37}$ y E. de Arteaga, Le Rivoluzioni del teatro musicale italiano (1783).

divulgadora y didáctica, muy en la línea del resto de su producción ensayística, concebida para la lectura dilettante de un público no especializado: "certi pensieri che hanno un certo di grazia originale, in lettere o piccioli saggi, la perdono, mi pare, nel metodico apparato d'un libro" (Opere, vol. VII, p. 336. Cito por M. Fubini, op. cit., p. 344). Así, Algarotti escribió otros ensayos referentes por ejemplo, a la pintura, a la arquitectura, al comercio, etc... siendo, sin duda el titulado Newtonianismo per le dame (1737) el que le hizo célebre. Esta superficialidad en el tratamiento de los temas le valió la crítica de especialistas como Baretti ("I nobili oziosi, non volendo apparire ignoranti, leggevano le operette del conte [Algarotti], le quali non hanno bisogno di studio né di dottrina e che trattando d'un po' di tutto, insegnavano a' nobili il modo di addottrinarsi in un po' di tutto" (M. Fubini, apud., p. 344). También Arteaga critica la brevedad de Algarotti: "Il celebre Conte Algarotti ne schizzò un breve Saggio [...]. Ma limitato unicamente alla pratica non volle, o non seppe risalire fino a' principj,..." (Rivoluzioni, vol. I, p. 24).

${ }^{35}$ El título completo es Dissertazione su le Poesie Drammatiche del Sig. Abate Pietro Metastasio, y es un compendio de la posterior reforma propuesta conjuntamente con Gluck. Partiendo de un elogio general de Metastasio, muestra una clara inclinación hacia la idea que el clasicismo francés mantenía respecto al melodrama. Calzabigi es también autor del melodrama satírico de los defectos del género, titulado L'opera seria (cfr. nota 28). En una carta al Mercure de France, en 1784, se manifiesta igualmente intransigente contra el melodrama moderno, al sostener "la necessità di tornare all'asciutta trama dei drammi greci ed al loro rapido e scultoreo fraseggiare, senza indulgere ai vezzi dei cantanti, evitando quelle 'bizzarre, armoniose filigrane' delle arie, e abolendo insomma 'tutto ciò che è stato introdotto di zotico, di barbaro, di stravagante nella nostra musica'". (F. Mollia, op.cit., pp. XV-XVI). Por último, Calzabigi respondió duramente a las críticas que Arteaga le hiciera en las Rivoluzioni. El texto de esta respuesta fue posteriormente publicado bajo el irónico título de Risposta che ritrovò casualmente nella gran città di Napoli il licenziato Don Santigliano di Gilblas y Guzman, y Torres, y Alfarace: discendente per linea paterna e materna da tutti quegli magnifici personaggi delle Spagne alla critica ragionatissima delle poesie drammatiche del C. de' Calsabigi fatta dal baccelliere D. Stefano Arteaga suo illustre compatriotto (Venecia, 1790).

36 Estos son los fragmentos más destacables de dicho "Prefacio": "Cuando acepté componer la música de Alcestes me propuse despojarla completamente de todos los abusos que, introducidos por la malentendida vanidad de los cantantes o por la excesiva complacencia de los maestros, desfiguran desde hace mucho tiempo la ópera italiana y vuelven ridículo y aburrido al más grandioso y más bello de todos los espectáculos. Pensé reducir la música a su verdadero oficio de servir a la poesía por la expresión y la situación de la fábula, sin interrumpir la acción ni entibiarla con inútiles adornos superfluos, y creí que debía proceder como el pintor que sobre un correcto y bien compuesto dibujo dispone la vivacidad de los colores y el bien repartido contraste de luces y sombras, realzando con ello las figuras sin alterar sus contornos. [...] Traté, en suma, de desterrar todos los abusos que de mucho tiempo a esta parte dañan el buen sentido y la razón. Pensé que la sinfonía debe preparar a los espectadores para la acción que va a representarse, e insinuar, por así decirlo, el argumento de la obra. Creí que mi mayor trabajo debía aplicarse a buscar una bella sencillez; y evité hacer alarde de dificultades en perjuicio de la claridad; con todo, no juzgué despreciable el descubrimiento de alguna novedad siempre que fuese naturalmente suministrada por la situación y la expresión. He aquí mis principios. Por suerte se prestaba a maravilla a mi propósito el libreto en que el célebre autor, imaginando una nueva exposición dramática, había sustituido los floreos, las descripciones, los parangones superfluos y las sentenciosas y frías moralejas por el lenguaje del corazón, las fuertes pasiones, las situaciones interesantes y un espectáculo siempre variado. El éxito ha justificado mis ideas y la universal aprobación en una corte tan ilustrada ha puesto de manifiesto que la simplicidad, la verdad y lo natural son los grandes principios de lo bello en todas las producciones de arte [...]. (Cito por Diccionario Bompiani, Barcelona, Planeta-Agostini, 1987, vol. 2)

37 Este ensayo también es, como la "Dissertazione" de Calzabigi, una introducción a una edición de las obras de Metastasio, publicada en Nápoles. Al igual que Arteaga, Mattei se declara admirador y defensor de Metastasio, pero reconoce que la evolución del lenguaje musical a lo largo del siglo ha ido haciendo de los textos metastasianos una estructura rígida y estrecha que deja poco espacio a la música: "S. Mattei giunge a proclamare la necessità che si tentino nuove vie, variando i metri, allungando i testi delle arie di sette, otto versi, 
Otros autores importantes de la época, que, si bien no trataron en profundidad la cuestión específica de la reforma del melodrama, sí están muy relacionados con la obra y los autores antes citados, ya que sostuvieron intensas polémicas con ellos, son: A. Eximeno (Dell'origine e delle regole della musica, 1774) $)^{38}$ fue otro jesuita español exiliado en Italia, y entre todos estos autores representa el punto extremo de aproximación a las ideas rousseaunianas sobre la música. Rechazó de plano la concepción pitagórica de la música y, en general, toda la obra de Rameau, ya que, según él, la música debe regirse por lo que agrada al oido y no a la matemática. Estas ideas le llevaron a sostener una fuerte polémica con el padre Martini, músico y autor de una Storia della musica (1757-1781), cuya posición era netamente racionalista-rameauiana, a favor de la existencia de unos principios eternos de la música, expresados en la armonía contrapuntística. Por último, V. Manfredini (Difesa della musica moderna e dei suoi celebri esecutori, 1788), también músico, polemizó con Arteaga ${ }^{39}$ y Martini. Defendía, con gran intuición, que el estado de la música de su tiempo debía ser aceptado como fruto de una evolución normal desde los tiempos de la música griega, en la que el dominio de la palabra sobre la música era total, pero que la tendencia posterior había llevado de forma inexorable a la autonomía de la música, a la música instrumental o pura.

En un próximo estudio se analizarán pormenorizadamente cada una de estas aportaciones. Aquí nos centraremos, aunque también de forma sintética, en la más significativa y prestigiosa de ellas, hecho quizá motivado porque no se limitó a ser una propuesta teórica de un literato, sino que fue llevada con brillantez a la práctica, en melodramas tales como Orfeo ed Euridice (1762) y Alceste (1767). Nos referimos a la reforma de C. W. Gluck y R. de' Calzabigi, reflejo de un ideal melodramático fundamentalmente ecléctico, que conciliaba determinados elementos de las tres líneas de pensamiento que se habían desarrollado hasta entonces en la crítica del melodrama (la clasicista, la enciclopedista y la literaria) en un modelo único. Por la época del estreno del Alceste, las posiciones radicales entre bufonistas y antibufonistas, y en general, entre los partidarios del melodrama italiano y el francés, se habían atenuado enormemente, ya que el primero había perdido parte de su fuerza espontánea y fresca, y el segundo había degenerado en su exceso moralista; de esta forma se hizo evidente a los partidarios de una y otra tendencia que ambas ofrecían aspectos aprovechables para la búsqueda de un modelo mejor, al tiempo que los defectos en una y otra se habían

o facendo anche arie di più strofe, per togliere a' maestri l'occasione di urtar sempre nello stesso" (Di Benedetto, op. cit., p. 388).

38 Esta obra fue traducida al español en 1796. Actualmente existe una edición moderna, Del origen y reglas de la música, a cargo de F. Otero (Madrid, Ed. Nacional, 1978). Vid. M. Batllori, op. cit., pp. 32-3.

${ }^{39}$ La historia de esta controversia es, básicamente, como sigue: Manfredini compuso, a partir de dos capítulos del vol. II de las Rivoluzioni un "Estratto" para publicarlo en Giornale Enciclopedico de Bolonia (num. XIII, abril 1786). Ello provocó la inmediata respuesta de Arteaga, a través de unas "Osservazioni", que a su vez generaron unas "Repliche" por parte de Manfredini, que esta vez consideraba las Rivoluzioni en su totalidad. El "Estratto" más las "Repliche" configuran lo que Manfredini publicó con el nombre de Difesa della musica moderna. Por último, Arteaga redactó unas "Risposte" a las anteriores "Repliche". Todos estos textos, tanto de Manfredini como de Arteaga, fueron incluidos a modo de apéndice en el vol. III de las Rivoluzioni en su edición boloñesa, y están igualmente reproducidos en la edición facsímil citada en la nota 1. 
extremado hasta el punto de haber llevado al melodrama a la frivolidad. La obra de Gluck y Calzabigi resultó ser el modelo anhelado dentro del agonizante neoclasicismo, y ello trajo como resultado la disolución paulatina del melodrama francés y la consolidación y mejora del melodrama italiano, que se erigió así en el modelo ilustrado de la ópera. Piccini fue el defensor de la causa francesa, sin apenas éxito ${ }^{40}$.

La síntesis conseguida por Gluck y Calzabigi es muy compleja y matizada. Como ya se ha dicho, en ella se concilian elementos propuestos no sólo por el clasicismo racionalista francés (defensa de la unidad dramática, la coherencia y la linealidad de la acción) y por los enciclopedistas (fortalecimiento de la expresividad de la música y búsqueda de un arte apasionado y auténtico por parte del autor), sino que también se dio acogida a determinadas propuestas de los literatos italianos, principalmente de Algarotti, entre las cuales debe destacarse la reafirmación del logocentrismo: el libreto debía continuar siendo el eje de la representación melodramática. No obstante, el punto de vista de Algarotti al respecto era más radical que el de Gluck y Calzabigi, ya que el primero mostraba una concepción analítica del melodrama, un compuesto de varias artes, entre las cuales la poesía campea sobre las demás. Gluck, por el contrario, concebía sintéticamente el melodrama: aún coexistiendo diversas artes que secundan a la poesía, todas actúan, incluida ésta, al servicio de un ideal superior, el de la expresividad dramática.

También son notables las diferencias entre Gluck y el clasicismo francés, debiéndose destacar su posición ante la concepción hedonista de la música, aún defendida por La Harpe y Marmontel, y rechazada de plano por Gluck. En cuanto a las propuestas del enciclopedismo que no fueron recogidas por Gluck están el extremo propugnado por Diderot de un retorno a la tragedia como manifestación mítico-religiosa que tuvieron los griegos, o la pretendida superioridad de la melodía sobre la armonía, es decir, la superioridad de lo espontáneo y el simple buen gusto a la hora de crear y valorar críticamente la música: una idea de la que los enciclopedistas derivaron el nacionalismo musical. Gluck, por el contrario, se mantuvo fiel al ideal de Rameau de la música como lenguaje universal, y creía en el rigor matemático como sistema invariable en el tiempo y en el espacio para obtener la belleza musical.

Gluck es el último defensor de la idea de una ópera internacional antes de que ésta fuera enterrada definitivamente por el Romanticismo. Por ello Gluck no abre, sino que cierra de forma gloriosa una época en la historia de la estética musical ${ }^{41}$. La obra de Gluck, así como

\footnotetext{
40 Piccini era músico. En realidad, los portavoces de su ideal de música fueron J. F. La Harpe, autor de unos artículos contra Gluck en el Journal de Politique et de Littérature (París, 1777), y A. F. Marmontel (Essai sur les révolutions de la musique en France, Paris, 1777). Piccini es autor de un "Elogio del Maestro Sacchini", en francés, reproducido en italiano en el vol. III de las Rivoluzioni (ed. facsímil citada en nota 1).

41 "Gluck puede haber llevado a su orquesta los acentos dramáticos más íntimos que brotan del alma de sus personajes. Sin embargo, estos seres, que son todavía los personajes míticos del teatro clásico (Orfeo, Alcestes, Ifigenia), carecen, como sus modelos, de movimiento, de acción. Su verdad expresiva es una verdad interna. Sus acentos resultan convincentes, palpitantes, pero ellos aún son estatuas. Es menester que el genio ligero, chispeante, vivo en el sentido más estricto de la palabra, como es el de Mozart, convierta a esas imponentes figuras marmóreas del teatro de Gluck en gentes de carne y hueso. Gluck encomendaba a su orquesta la traducción real del alma de esos personajes. En el teatro de Mozart los personajes se expresan directamente por sí mismos...". A. Salazar (Síntesis de Historia de la Música. Cito por J. Zamacois, op. cit., p. 117).
} 
las aportaciones teórico-críticas de la línea humanista en torno al melodrama, incluida la de Arteaga, constituyen el último intento, en gran parte baldío, por hacer mantener a la poesía su dignidad frente a lo que ya se aceptaba como imparable ascenso de la música. Estas palabras de Mozart son totalmente elocuentes al respecto: "Tanto más debe gustar una ópera cuanto mejor elaborado esté el plan de trabajo, con la letra escrita sólo para la música"42. La irrupción del Romanticismo también era imparable, y erigió a la música como la mayor de todas las artes, y por tanto, al melodrama como una manifestación primordialmente musical.

Con el Romanticismo se apaga el espíritu polémico en torno al melodrama que había caracterizado a la crítica de todo el siglo XVIII. Arteaga posiblemente sea el último representante de un filón de literatos y críticos que se sienten autorizados a determinar los destinos de la música, siempre en relación con la poesía. No hubo literato romántico que dejara de pronunciarse sobre la música, pero sus escritos destilaban una concepción muy diferente de ésta, la del literato que observa y admira la música a distancia, como un ideal inalcanzable:

Sembra quindi di poter concludere che il rapporto tra letteratura e musica italiana [...] dimostri almeno [...] una sostanziale concordia: nel senso che la prima conferma pienamente, con l'argomento del silenzio, la tendenza evolutiva dell'altra. Queste riflessioni infatti possono forse aiutarci a comprendere come, spostatosi altrove col volgere del secolo il centro dell'attenzione nelle questioni riguardanti la musica, al clamore delle polemiche subentrerà quasi d'improvviso un sostanziale disinteresse, e il capitolo "musica" scomparirà, o sarà tutt'al più relegato ai margini estremi della storia letteraria d'Italia: di una storia almeno intesa come quella "dell'origine e dei progressi delle scienze tutte" secondo il programma del Tiraboschi ${ }^{43}$.

En definitiva, desde la Camerata Fiorentina hasta Mozart, el complejo mundo de las teorías que rodearon a la ópera en sus dos primeros siglos de existencia se nos presenta apasionante. Esteban de Arteaga brilla con luz propia a finales de dicho período con una obra vasta y densa, miscelánea, polémica en su tiempo, ensalzada pero apenas estudiada en el nuestro. Hoy, más de dos siglos después de su publicación, una edición crítica de las Rivoluzioni permitirá valorar con mayor conocimiento de causa la importancia de esta obra en el marco que hemos descrito someramente en este artículo.

\footnotetext{
42 Carta a su padre. Cito por Zamacois, op. cit., p. 116, nota 2.

43 Di Benedetto, op. cit., p. 372.
} 